\title{
AGRONEGÓCIO E PODER POLÍTICO: POLÍTICAS AGRÍCOLAS E O EXERCÍCIO DO PODER NO BRASIL
}

\author{
Celso Donizete Locatel ${ }^{1}$ \\ Fernanda Laize Silva de Lima ${ }^{2}$
}

\section{Resumo}

As raízes históricas de formação do Brasil estão assentadas sobre bases agrárias e a agricultura sempre teve importância fundamental na economia nacional e na reprodução do poder político no cerne do Estado brasileiro. Nesse sentido, a forma de organização da agricultura e o processo de desenvolvimento brasileiro resultam do sistema de privilégios posto a serviço do capital agromercantil, desde o período colonial. A partir do final da ditadura militar, em 1984, a oligarquia rural brasileira cria a União Democrática Ruralista e passa a ter as campanhas de seus representantes financiadas por empresas dos setores mais lucrativos do agronegócio. De acordo com dados do Departamento Intersindical de Assessoria Parlamentar (2011-2015), 149 deputados federais e 18 senadores integram a bancada ruralista, perfazendo 29\% da Câmara e 22\% do Senado, na legislatura de 2010-2014. Na legislatura 2015-2018, a bancada ruralista possui 222 parlamentares, sendo 201 deputados e 11 senadores, correspondendo a 39\% da câmara e a 13\% do Senado, o que garante a aprovação de Projetos e Leis que atendam aos interesses dos agentes hegemônicos do agronegócio brasileiro.

Palavras-Chave: Estado; política pública; agronegócio; poder; bancada ruralista, Brasil.

\section{AGRIBUSINESS AND POLITICAL POWER: AGRICULTURAL POLICY AND THE EXERCISE OF POWER AT THE FEDERAL SCALE IN BRAZIL}

\begin{abstract}
The historical roots of social formation in Brazil are based on agrarian societies and the agriculture has always played a fundamental role in the national economy and in the political power reproduction at the heart of the Brazilian state. In this sense, the form of the agriculture organization and the Brazilian development process are the results of the privileges made available to the agro-mercantile capital, since the colonial system. At the end of the military dictatorship in 1984, the Brazilian rural oligarchy creates the Rural Democratic Union (UDR) and then have their campaigns financed by the most profitable companies of agribusiness. According to data from the DepartamentoIntersindical de AssessoriaParlamentar (20112015), 149 federal deputies and 18 senators comprise the rural group, comprising $29 \%$ and
\end{abstract}

\footnotetext{
1 Professor do Departamento de Geografia e do Programa de Pós-graduação e Pesquisa em Geografia da Universidade Federal do Rio Grande do Norte. Email: celso.locatel@gmail.com.

${ }^{2}$ Mestre em Geografia pelo Pós-graduação e Pesquisa em Geografia da Universidade Federal do Rio Grande do Norte. Email: fernanda.laize@gmail.com
}

Sociedade e Território - Natal. Vol. 28, N. 2, p. 57 - 81. Jun./Dez. de 2016 
$22 \%$, respectively, the members of the Chamber and Senate to the legislature 2010-2014.In the 2015-2018 legislature, the rural group has 222 parliamentarians, 201 deputies and 11 senators, corresponding to $39 \%$ of the Chamber and $13 \%$ of the Senate, which guarantees the approval of projects and laws that aim the interests of hegemonic agents of the Brazilian agribusiness.

Keywords: State; public policy; agribusiness; power; worktop (group) rural, Brazil.

\section{AGRONEGOCIO Y PODER POLÍTICO: POLÍTICAS AGRÍCOLAS Y EL EJERCICIO DEL PODER EN BRASIL}

\section{Resumen}

Las raíces históricas de formación de Brasil están asentadas sobre bases agrarias yla agricultura siempre tuvo una importancia fundamental en la economía nacional y en la reproducción del poder político en el seno del Estado brasilero. En tal sentido, la forma de organización de la agricultura y el proceso de desarrollo brasilero resultan del sistema de privilegios puesto al servicio del capital agromercantil desde el período colonial. A partir del fin de la dictadura militar, en 1984, la oligarquía rural brasilera crea la União Democrática Ruralista y pasa a financiarlas campañas de sus representantes por medio de empresas de los sectores más rentables del agronegocio. De acuerdo con datos delDepartamento Intersindical de Assessoria Parlamentar (2011-2015), 149 diputados federales y 18 senadores integranla bancada ruralista, alcanzando el $29 \%$ de la Cámara y $22 \%$ del Senado, en la legislatura de 2010-2014. En la legislatura 2015-2018, la bancada ruralista posee 222 parlamentarios, siendo 201 diputados y 11 senadores, correspondiendo a 39\% de la Cámara y a 13\% del Senado, lo que garantizala aprobación de Proyectos y Leyes que atiendanlos intereses de los agentes hegemónicos del agronegocio brasilero.

Palabras-clave: Estado; política pública; agronegocio; poder; bancada ruralista; Brasil

\section{INTRODUÇÃO}

As oligarquias rurais sempre tiveram grande peso político no contexto nacional brasileiro, dado a importância econômica da agricultura e dos setores produtivos a ela relacionados, que compõem o que se denomina de agronegócio, representando $21,46 \%$ da econômica nacional, contribuindo com 1.267.241 milhões de reais para o Produto Interno Bruto (PIB), em 2015, de acordo com dados Cepea/Esalq (2015) ${ }^{3}$.

\footnotetext{
3 Os dados encontram-se disponíveis no site do Centro de Estudos Avançados em Economia Aplicada ESALQ/USP. Disponível em:<http://www.cepea.esalq.usp.br/br/pib-do-agronegocio-brasileiro.aspx $>$. Acesso em 01 novembro de 2015.
} 
Diante dessa realidade, faz-se necessário um esforço teórico-metodológico para a análise do poder exercido pelos ruralistas ${ }^{4}$, empresários e latifundiários, no direcionamento das políticas agrícolas no Brasil que, mesmo após as mudanças apresentadas no período pósditadura militar (após 1984), continuam privilegiando a expansão do agronegócio empresarial, principalmente do setor sucroalcooleiro, bovinocultor, silvicultor e sojicultor, em detrimento de benefícios aos camponeses.

Para tanto, além de uma revisão da literatura sobre as políticas agrícolas no Brasil e sobre a forma de atuação dos grupos hegemônicos no cenário político nacional, também foi indispensável levantar informações sobre o sistema eleitoral e os mecanismos de financiamento de campanhas. Além desse procedimento, depois de identificados todos os deputados e senadores que compõem a bancada ruralista no Congresso Nacional, foi feito um levantamento de dados dos financiadores das campanhas políticas, junto ao banco de dados do Superior Tribunal Eleitoral (STE).

\section{AGRICULTURA E PODER DAS OLIGARQUIAS RURAIS NO BRASIL: Uma aproximação}

As raízes históricas da formação socioterritorial do Brasil estão assentadas sobre bases agrárias e a agricultura sempre teve importância fundamental na economia nacional e na reprodução do poder político no cerne do Estado nacional. Para ilustrar isso basta lembrar que as forças políticas que impulsionaram a proclamação da República (1889) emanaram, em parte, das oligarquias rurais, formadas pelos "barões do café" ${ }^{5}$ e pecuaristas, no Sudeste, e pelos senhores de engenho no Nordeste. Da mesma forma, o primeiro período republicano, de 1889 a 1930, denominado de República Velha, que é marcada pela política "Café com Leite", caracterizada pela alternância no poder central (Presidência da República) de um paulista e um mineiro (FAORO, 2001), representantes da oligarquia rural dos estados de São Paulo e de Minas Gerais.

\footnotetext{
${ }^{4}$ São classificados como integrante da bancada (lobby) ruralista aquele parlamentar que, mesmo não sendo proprietário rural ou de empresas ligadas a algum setor do agronegócio, assume sem constrangimento a defesa dos pleitos da bancada, não apenas em plenários e nas comissões, mas também em posicionamentos públicos assumidos em entrevistas à imprensa e nas manifestações de plenário (DIAP, 2011).

${ }^{5}$ Proprietários de terras e produtores de café, com grande poder político no período Imperial no Brasil (1822 a 1889), que compravam títulos de nobreza.
} 
Do ponto de vista político, com o início do Estado Novo ${ }^{6}$, em 1930, ocorre uma reconfiguração do poder político, porém sem o alijamento das oligarquias rurais, que por meio de um pacto populista conseguem permanecer no poder, agora o compartilhando com outros seguimentos da sociedade brasileira. Esse novo pacto político foi denominado de populista, por tentar congregar diferentes interesses de classes.

O populismo no Brasil só pode ser entendido como uma adequação da expressão política dos interesses determinados e emanados pelos diferentes grupos e classes sociais, seja qual for sua forma. Pode ser compreendido em dois períodos: o primeiro que compreende desde 1930 a 1945 e outro de 1945 a 1964. O primeiro período é marcado por acontecimentos que estão vinculados à necessidade de reduzir o poder político e econômico dos setores agroexportadores e importadores, baseado na necessidade de constituir-se um sistema institucional adequado à economia urbano-industrial que estava se estruturando, como ressaltam Locatel e Locatel (2013).

No período entre 1945 e 1964 esse processo se torna mais complexo, pois o setor industrial se desenvolve amplamente. Nesse período alguns grupos sociais (ligados à indústria e ao setor financeiro) começam a ter mais importância como categoria política. A luta pela participação vai se acirrando cada vez mais. De acordo com Ianni (1975), é nesse contexto que se coloca o problema dos encadeamentos entre movimentos de "massas" e partidos políticos no Brasil.

Segundo Castro (1971), o populismo parecia conter um processo dialético, através do qual quanto mais forte o movimento popular, mais forte o controle do Estado sobre a sociedade. Além disso, foi uma ideologia de poder, representada por uma burguesia, que consegue mascarar a supremacia burguesa através da articulação que vai dominando as outras classes, que também chegam a acreditar que estão no poder, participando politicamente.

No Brasil o regime populista não é oligárquico, porém as oligarquias continuaram exercendo funções de hegemonia social e política no âmbito local e regional e se encontravam representadas na esfera federal. A burguesia industrial vai se fortalecendo, no entanto, isso não significou que as tradicionais oligarquias agrárias fossem afastadas do poder. Estas mantiveram uma forte presença no Congresso Nacional, foram objetos de políticas econômicas específicas e, principalmente, tiveram resguardo, do ponto de vista legal, o absoluto controle sobre a propriedade da terra. E, enquanto permanecer esta estrutura

\footnotetext{
${ }^{6}$ Período da história republicana brasileira que vai de 1930 a 1964, marcado pela prática populista.
} 
fundiária do país, segundo Leal (1997, p. 257), as formas de poder, como o coronelismo ${ }^{7}$, continuarão sendo sustentadas (LOCATEL; LOCATEL, 2013).

A forma de organização da agricultura e o processo de desenvolvimento brasileiro, segundo Furtado (1972), resultam do sistema de privilégios posto a serviço do capital agromercantil, desde o Período Colonial, que conseguiu se manter através do controle da propriedade da terra, tornando-se uma das principais causas da concentração da renda e da reprodução da pobreza no país.

Mesmo diante do amplo debate em torno do direcionamento das políticas públicas adotadas no Brasil, a partir da década de 1960, e das críticas contundentes sobre os privilégios garantidos pelo Estado aos senhores de terras, tornaram-se hegemônicas ideias como as de Paiva (1954), que defendia que os instrumentos de política agrícola deveriam privilegiar o aumento da oferta agrícola e, para tanto, o foco das políticas deveria ser a adoção de políticas de preços mínimos e de crédito rural. Porém, isso se aplicaria apenas às culturas que melhor reagem à intensificação do uso das novas técnicas e sejam susceptíveis à mecanização.

Assim, para Paiva (1954), a superação da instabilidade dos preços dos produtos agrícolas era condição sinequa non para a modernização do setor agrícola, já que a flutuação de preços não fornecia segurança para a incorporação de insumos e equipamentos modernos, principalmente aqueles que exigiam grandes inversões de capitais, como as máquinas e implementos. A partir dessa concepção, nota-se a deliberada exclusão dos agricultores camponeses descapitalizados das políticas públicas do Estado brasileiro.

Sendo assim, Paiva (1971) considera que o problema estrutural, ou seja, a concentração fundiária, não interfere no processo de modernização da agricultura. Logo, para o autor, as propostas de reforma agrária não são a saída adequada para os problemas do campo, uma vez que são as grandes propriedades, mesmo com muitos obstáculos, que têm investido em melhorias tecnológicas, apesar da inexistência de apoio adequado dos órgãos de assistência e financiamento, o que demonstra todo o conservadorismo desse modelo de desenvolvimento rural que, a partir de meados da década de 1960, passou a prevalecer, na formulação de políticas públicas para a agricultura no Brasil.

\footnotetext{
${ }^{7}$ [...] "as raízes do coronelismo já estavam sedimentadas no Império e, com a República, o coronel apenas amplia o seu papel dentro da nova estrutura política. Somente com o desenvolvimento da urbanização e da industrialização, o poder coronelístico entra em declínio, isto por volta dos anos 40, sem, contudo, pode-se falar em seu desaparecimento" (JANOTTI, 1992).
} 
Diante desse processo, à agricultura foram atribuídas algumas funções como geração e ampliação de um excedente de alimentos e matérias-primas, liberação de mão de obra barata, constituição de um mercado consumidor e transferência de capitais para o setor urbanoindustrial (CASTRO, 1969). Assim, as funções atribuídas à agricultura foram estabelecidas de acordo com os modelos de desenvolvimento rural formulados pelos defensores da "tese da modernização" da agricultura, pois, para eles, é só através da implementação desse processo que o setor agrícola passaria a responder adequadamente ao modelo de desenvolvimento econômico adotado no país (LOCATEL, 2004).

O direcionamento dado às políticas públicas agrícolas no Brasil, em especial a partir de 1965, marca uma busca por mudanças na forma de atuação do Estado, com vista à manutenção de privilégios para as antigas oligarquias rurais, que sempre estiveram presentes no cerne do Estado, a partir da ocupação de cargos tanto no quadro executivo, assim como no legislativo.

\section{Redefinição das relações de poder, descentralização administrativa após 1988 e as políticas públicas para a agricultura}

O desenvolvimento do setor agropecuário, ocorrido no Brasil no período entre 1930 e 1960, foi marcado por um padrão de crescimento agrícola, apoiado na expansão horizontal com baixo nível tecnológico e pela ação do Estado, através de políticas de colonização para o crescimento da economia agrícola, voltando a produção para o mercado interno (SORJ, 1980), porém com a participação das oligarquias rurais que tiveram seus interesses atendidos, como em períodos anteriores.

A estrutura de poder montada após a chegada dos militares ao poder, em 1964, se deu a partir de um novo pacto político, no qual as oligarquias rurais mantiveram seus privilégios e o poder político, garantindo que os Governos Militares incluíssem nas pautas de atuação (projetos e programas) as reivindicações desse seguimento da sociedade.

Porém, a crise apresentada pelo Estado desenvolvimentista, no final da década de 1970, provocou o início de um processo de transformação no espaço rural. O crédito subsidiado como instrumento de indução da agricultura empresarial chega ao fim em 1984, quando os empréstimos concedidos ao setor agrário passaram a ter a aplicação integral da correção monetária mais juros reais positivos de 3\% ao ano (LOCATEL, 2004).

Na década de 1970, tem-se o período de maiores subsídios para o Sistema Nacional de Crédito Rural (SNCR), com uma taxa nominal de juros cobrada nos financiamentos agrícolas 
fixadas em $15 \%$ ao ano, enquanto que as taxas de inflação chegavam até $28,7 \%$ (valor de 1974) (LOCATEL, 2004).

No entanto, o crédito subsidiado associado a outras políticas públicas, propiciou a incorporação de novas técnicas à agricultura (máquinas, insumos) e a manutenção da estrutura agrária arcaica, não contribuindo efetivamente para a promoção do desenvolvimento nacional, além de provocar marginalização socioeconômica de grande quantidade de brasileiros. Com a implementação de uma política sistemática no decorrer das décadas de 1950, 1960 e 1970 foram mantidos ritmos constantes de crescimento, ocorrendo ajustamentos para adaptar a realidade aos indicadores de progresso. Os processos de industrialização e urbanização foram intensificados, o país se tornou exportador de bens manufaturados e houve significativa ampliação das exportações de matérias-primas de origem agrícola.

Nesse contexto a sociedade brasileira passa a apresentar sinais de modernidade, havendo a implantação de infraestrutura de transporte e energia. No entanto, grande parte da população não usufrui das vantagens propiciadas por esta modernidade. A massa marginalizada demanda trabalho e dignidade. O desemprego é estrutural, grande parte da população marginalizada não possui qualificação profissional e os níveis de educação formal são baixos. Para a população com tal perfil, a alternativa mais barata de garantia de ocupação e renda reside na exploração agrícola, ou seja, na terra que é fator de produção abundante, dada a dimensão territorial e as condições naturais do país, e ao mesmo tempo, escasso, em razão do monopólio exercido pelos grandes proprietários rurais.

Constata-se ainda que este processo chamado de modernização da agricultura não ocorreu da mesma maneira para todos os produtores rurais e todos os tipos de cultivos, acirrando uma pobreza rural que não tem sua origem na própria atividade agrária moderna, mas na dinâmica sociopolítica que incentivou a concentração da propriedade, viabilizando a exclusão - pauperização e semi-proletarização - dos produtores tradicionais, na sua maioria agricultores camponeses.

Até meados da década de 1980, pode-se considerar que o Estado foi o principal agente indutor do setor agrícola, com a implementação de políticas de modernização da agricultura, o que definia a dinâmica do setor. Já o período compreendido entre a segunda metade da década de 1980 e o início da década de 1990 foi marcado pela ausência de políticas indutoras para a agropecuária. Pode-se afirmar então que na década de 1980 ocorreu o abandono dos instrumentos de política agrícola (garantia de preços mínimos, estoques reguladores, crédito 
agropecuário). Além desse aspecto, houve diminuição dos recursos públicos destinados à infraestrutura rural, à pesquisa agropecuária, à assistência técnica.

No entanto, durante décadas as políticas de crédito generosas, os subsídios aos financiamentos e às compras de máquinas e insumos tenderam a beneficiar um grupo formado pelos grandes produtores, empresários rurais, latifundiários e especuladores, as indústrias à montante e à jusante da agricultura, que lucraram com suas atividades, por constituírem uma elite que influenciava (e ainda influencia) no processo formador das políticas agrícolas, enquanto os agricultores camponeses e o trabalhador rural permaneceram à margem do processo formador das políticas agrícolas, vivem a acentuação da pobreza e da miséria herdadas de fases anteriores ${ }^{8}$.

Com o fim da ditadura militar, em 1985 inicia-se a fase da "redemocratização", com a convocação da Assembleia Nacional Constituinte, que tinha como objetivo elaborar uma nova Constituição para o País. Nesse período, há uma redefinição de forças políticas, com o estabelecimento de um novo pacto, onde os setores hegemônicos se alinham para estabelecer oposição às forças populares que emergiram, principalmente os partidos de esquerda e movimentos sociais que reivindicavam justiça social, desencadeando uma campanha por reforma agrária.

Nesse contexto, há uma tendência à organização de diversos seguimentos da sociedade, na busca de maior poder político. Surgem assim dois movimentos antagônicos, um dos trabalhadores sem terras (MST), fundado em 1984, tendo como aliados representantes da Igreja Católica, adeptos da Teologia da Libertação, e o Partido dos Trabalhadores, criado em 1980. O outro movimento que surge é o dos grandes e médios proprietários de terras que criam, em 1985, a União Democrática Ruralista (UDR). Essas duas forças antagônicas conseguem marcar presença na Assembleia Constituinte (1985-1988), e parte de suas reivindicações foram incorporadas ao texto constitucional, porém, prevalecendo os interesses do grupo hegemônico, no caso os ruralistas.

Um desdobramento da Constituição de 1988 foi o processo de descentralização do poder do Estado, com a transferência de responsabilidades para as Unidades da Federação e para os municípios. Como consequência disso, verifica-se uma queda na rentabilidade e maior instabilidade no setor agrícola. Este processo de descentralização tem se mostrado insuficiente para estimular o desenvolvimento das áreas rurais, uma vez que, em muitos casos, houve um

\footnotetext{
${ }^{8}$ Sobre esse assunto ver Delgado (1985), Müller (1993) e Muller (1994).
} 
processo de sucateamento da estrutura de pesquisa, assistência técnica e extensão rural, que foi implementada a partir da década de 1960, com a adoção das políticas de modernização da agricultura brasileira.

Esse sucateamento está associado ao fato de que a transferência de responsabilidades e competências para o âmbito estadual e municipal não foi acompanhada pela criação de novas instituições e pelo surgimento de novos agentes públicos capazes de elaborar políticas e programas adequados à realidade local ou regional, os quais deveriam promover o desenvolvimento com maior equidade.

A partir de 1999, com a criação do Ministério do Desenvolvimento Agrário ${ }^{9}$, passou a existir duas linhas de políticas públicas para o campo brasileiro. A primeira de caráter estritamente setorial, executada pelo Ministério da Agricultura, que tem como objetivo a maximização da competitividade do agronegócio. Para tanto, a meta principal do setor primário, formado pela agricultura, pecuária, silvicultura e pesca, é a redução de custos de produção tornando-se necessária a incorporação crescente de tecnologia e uma especialização das unidades de produção, o que gera a redução dos postos de trabalho e uma demanda por mão de obra qualificada. A absorção do excedente de força de trabalho resultante desse processo fica a cargo de outros setores da economia ou de setores sociais (VEIGA, 2001).

A segunda, ainda que mantenha o caráter setorial, tem como objetivo maximizar as oportunidades de desenvolvimento local/territorial em todas as áreas rurais, ao contrário do primeiro projeto, que busca a especialização que gera redução de postos de trabalho, esse tem como meta a diversificação das economias locais, a começar pela agropecuária, tentando dinamizar o rural através da diversidade multissetorial e da salubridade dos alimentos produzidos e da preservação ambiental, que são elementos que se convertem em vantagens competitivas na atualidade.

A partir de 1995, no governo de Fernando Henrique Cardoso, são retomadas várias políticas para o agronegócio, incluindo o financiamento agrícola com taxas de juros subsidiadas. Nesse mesmo período, com vistas a atender parte das reivindicações populares, em especial da Federação Nacional dos Trabalhadores na Agricultura Familiar (FETRAF), assim como do MST, são criadas políticas para a agricultura campesina, como por exemplo, o

\footnotetext{
${ }^{9}$ Criado em 25 de novembro de 1999 pela Medida Provisória n ${ }^{\circ}$ 1.911-12, após o massacre de Eldorado dos Carajás, e sua última estrutura regimental foi definida pelo decreto $\mathrm{n}^{\circ} 7.255$ de 4 de agosto de 2010 . Esse ministério foi extinto em 30 de maio de 2016, pelo Decreto ${ }^{\circ}$ 8780, assinado pelo governo provisório de Michel Temer. Parte das funções do MDA foi transferida para a Casa Civil.
} 
Programa Nacional de Fortalecimento da Agricultura Familiar (PRONAF). Vale destacar que tais medidas visam muito mais reduzir as tensões sociais, do que de fato resolver os problemas sociais vinculados à agricultura e ao meio rural.

Nota-se, no entanto, um desequilíbrio de poder na esfera federal e, com isso, mesmo havendo políticas específicas para a agricultura familiar, os privilégios são mantidos para os grandes e médios produtores rurais. No ano agrícola de 2013/14 o valor total destinado para o Plano Safra da Agricultura Familiar foi de R\$ 21 bilhões (executado pelo Ministério do Desenvolvimento Agrário), enquanto que para o agronegócio, através do crédito agrícola do Plano Agrícola e Pecuário, foram disponibilizados R 136 bilhões (executado pelo Ministério da Agricultura). Já no ano agrícola de 2015/2016 o Plano Safra da Agricultura Familiar teve dotação orçamentária de R \$ 22,1 bilhões, enquanto que Plano Agrícola e Pecuário o valor foi de R\$ 187,7 bilhões. Percebe-se que entre o final da legislatura 2011-2014 e o início da legislatura 2015-2018, da mesma forma que houve um aumento expressivo da bancada ruralista, ocorreu um aumento de $38 \%$ no financiamento público da agricultura empresarial, enquanto que o valor para o financiamento para a agricultura familiar camponesa permaneceu praticamente inalterado.

Contudo, é válido destacar que mesmo recebendo a menor parte desses recursos, esse grupo de produtores rurais que corresponde à chamada agricultura familiar, inclui $85 \%$ dos estabelecimentos agropecuários, ocupando uma área total que compreende aproximadamente $30 \%$ das terras agricultáveis do território brasileiro, respondendo por $38 \%$ da produção agropecuária no país e totalizando 77\% dos empregos gerados nesse setor. Além disso, são provenientes dessa agricultura familiar cerca de $70 \%$ da produção dos itens básicos da alimentação da população brasileira, assegurando o abastecimento do mercado interno, ao contribuir com quase a totalidade da produção de feijão, hortaliças, mandioca e parte significativa do arroz, do milho e do leite (IBGE, 2006). É preciso que se ressalte também que cerca de $80 \%$ desses estabelecimentos de agricultura familiar no Brasil não possuem acesso adequado aos recursos e insumos produtivos, não podendo, portanto, ser considerado um modelo ineficiente, como muitos defensores do agronegócio afirmam.

\section{A UNIÃO DEMOCRÁTICA RURALISTA E OS MECANISMOS DE REPRODUÇÃO DE PODER}

Criada no ano de 1985, a União Democrática Ruralista (UDR) surgiu em um contexto de transição e debates acerca da reforma agrária na República Nova, enquanto uma reação de 
contraposição da elite rural às propostas reformistas e ao posicionamento do governo favorável à realização da reforma agrária. O propósito consistiu em criar uma instituição social capaz de representar os interesses da "classe rural", embora representasse apenas algumas categorias de produtores, sobretudo os grandes proprietários de terra, constituindo-se em um instrumento das novas formas de poder das históricas oligarquias rurais e políticas.

A UDR emerge como resposta as ações sistêmicas das organizações dos trabalhadores no campo, com o surgimento do MST, em 1984, e também pelo papel da Igreja Católica, a partir das Comunidades Eclesiais de Base (CEBS) e da Comissão Pastoral da Terra (CPT), que colocaram em evidência novamente para toda a sociedade a questão da concentração fundiária e a necessidade de uma distribuição mais justa da terra. Foi nesse momento de transição da ditadura que se colocava a discussão na sociedade, em torno do I Plano Nacional de Reforma Agrária (PNRA).

Associado a isso, por entenderem que as estruturas representativas existentes não mais atendiam às demandas e interesses patronais no campo, conformou-se uma organização que congregou os setores mais conservadores, ao qual Bruno (1996) denominou de "núcleo duro", visto que as bases sociais da UDR estavam representadas, principalmente, por pecuaristas do eixo Goiás-São Paulo-Minas Gerais que, em geral, exerciam atividades extensivas em suas propriedades, pouco integradas com os setores mais eficientes e agroindustriais, logo temiam sendo classificados como não produtivos e tendo suas propriedades passíveis de desapropriação para a realização de assentamentos de reforma agrária.

Além de contarem com o apoio de lideranças parlamentares expressivas, tais como Roberto Cardoso Alves, Alison Paulinelli, José Egreja, Luiz Eduardo Magalhães, Gasthoni Righi, Ricardo Fiuza, José Lourenço, Rosa Prata, bem como com o apoio dos usineiros, dos evangélicos, dos banqueiros e industriais favoráveis à propriedade fundiária, contaram também com o apoio de multinacionais. Alguns fatores asseguraram a legitimidade da UDR como a principal entidade patronal atuante durante a construção do I PNRA, como a presença de uma militância organizada, com forte caráter propagandista (ANDRADE, 2013).

A presença de Ronaldo Caiado ${ }^{10}$ à frente da UDR foi destacada pela mídia como uma liderança jovem, letrada, formada em medicina e capaz de realizar discursos que valorizavam e mobilizavam os produtores rurais. Vindo de uma das mais tradicionais famílias pecuaristas

$\overline{10}$ Desde 1990 ocupa cargos eletivos de deputado pelo estado Goiás e, atualmente, Senador da República. 
do estado de Goiás, foi o principal mentor e presidente da UDR, candidatando-se à presidência da República, em 1989 (BRUNO, 1996).

A militância e engajamento da UDR também garantiram sua força, ao possibilitar um conjunto de intervenções políticas, tais como as marchas cinematográficas, as passeatas, os acampamentos em propriedades ameaçadas de "invasão" pelos movimentos sociais, a realização de leilões de gado, uma vez que estes eventos permitiam a arrecadação de fundos para a organização e se constituíam em espaços de difusão do seu discurso político junto às suas bases sociais (MENDONÇA, 2008).

$\mathrm{Na}$ Constituinte, a bancada ruralista defendeu o monopólio absoluto da propriedade; a insuscetibilidade da desapropriação de propriedades consideradas produtivas; considerou o aumento da tributação das terras um instrumento claramente punitivo e arbitrário; além de ter sido contra a fixação de limites para a propriedade rural. Segundo Carneiro (2008), as manifestações feitas pela UDR, marcadamente presentes nos discursos de Caiado, apontavam como demandas a manutenção e ampliação da legislação em defesa do direito a propriedade privada; a repressão estatal aos movimentos de luta por terra; o cumprimento de reintegrações de posse; as políticas restritivas a uma reforma agrária e; as medidas judiciais favoráveis aos grandes proprietários de terra.

Os protestos contra o I Plano Nacional de Reforma Agrária na Nova República, e as manifestações em torno da Constituinte de 1988, em que a UDR se notabilizou e obteve êxito apenas evidenciaram que os grupos dominantes procuraram se unir na defesa absoluta da propriedade privada da terra, ao mesmo tempo em que exigiram do Estado um posicionamento em favor de seus interesses e de sua proteção jurídica, política e até mesmo repressiva. A UDR contribuiu para dificultar ainda mais a execução do plano de reforma agrária, visto que apenas $6 \%$ das famílias foram assentadas do total de um milhão famílias, previsto pelo I PNRA (CARNEIRO, 2008).

A defesa do monopólio fundiário, por sua vez, passa por enfrentamentos diretos com os trabalhadores sem-terra e, no final do ano de 1987, momento de decisões e votações sobre a Reforma Agrária e quando se intensificaram as ocupações de terra, a postura ofensiva antirreformista da UDR também se intensificou, quando Caiado afirmou que havia no campo brasileiro uma verdadeira guerra, buscando justificar o uso da força e da violência pela UDR, esta enquanto entidade de legítima defesa da produção e da propriedade (BRUNO, 1996). Nesse sentido, "Caiado é o exemplo mais acabado de autoritarismo e da postura sempre 
ofensiva daqueles que desprezam a negociação" (BRUNO, 1996, p. 81), agindo sempre com intimidação, agressividade e confronto.

A maneira como foi organizada a UDR - como um "movimento social" dos ruralistas, autônomo e não parlamentar - possibilitou que sua atuação ocorresse de formas bastante diversas, como a partir da formação de milícias rurais armadas em defesa das propriedades contra as "invasões" dos Sem-Terra; a organização de apoio jurídico aos proprietários; e ao aporte financeiro a parlamentares filiados à organização (ANDRADE, 2013). O uso da força pela UDR, como uma opção para "solucionar" e "proteger" a grande propriedade é, para Bruno (1996, p. 75), a sua marca registrada, em que a UDR "atualizou o uso da pistola e incentivou a formação de milícias privadas". Embora a violência no campo seja um dado histórico no Brasil, a novidade estava na justificativa dada pela UDR para legitimar sua prática, por parte dos fazendeiros e suas milícias.

Mesmo após a constituinte, a violência foi utilizada para impedir as vistorias do Instituto Nacional de Colonização e Reforma Agrária (INCRA) e as ocupações, sendo incentivada pela própria UDR a aquisição de armas pelos proprietários de terra. Ao refletir sobre essa realidade Bruno (1996) destaca que a morte do padre Josimo ${ }^{11}$, no ano de 1986, o assassinato de Chico Mendes ${ }^{12}$ e o massacre de Corumbiara (RO), em 1995, permitiram que a sociedade brasileira conhecesse a face violenta da UDR. Em toda a década de 1980, proprietários de terra de todas as regiões do país, descontentes com as ocupações, se organizaram para angariar fundos e comprar armas para se "defender" da reforma agrária.

Outra estratégia bastante utilizada pela UDR consistiu na desvalorização pública de seus adversários, por meio de sua lógica discursiva, que buscava, por um lado, fragilizá-los e desqualificá-los e, por outro, criar uma identidade patronal rural. O MST, a Igreja Católica e o Partido dos Trabalhadores figuraram como seus principais inimigos, em especial o primeiro, em razão de possuir uma grande capacidade de mobilização dos trabalhadores e também por dispor de um projeto político resistente às pressões e à cooptação das elites políticas e da

\footnotetext{
11 Ele foi assassinado, no dia 10 de maio de 1986, ao entrar na sede da CPT em Imperatriz, Maranhão, depois de diversas ameaças e de um atentado.

${ }^{12}$ Francisco Alves Mendes Filho, assassinado em 22 de dezembro de 1988, foi um seringueiro, sindicalista e ativista ambiental brasileiro. Lutou pelos direitos seringueiros da Bacia Amazônica, cujos meios de subsistência dependiam da preservação da floresta e suas seringueiras nativas. Esse ativismo ecológico lhe valeu fama internacional e muitos inimigos políticos.
} 
própria UDR. Nesse momento, o MST, a esquerda e a Igreja foram responsabilizados pela ideologização da questão agrária, a violência no campo e a própria emergência da UDR.

O conflito direto entre MST e UDR se tornou evidente, principalmente, a partir da década de 1990, quando cerca de 700 famílias de trabalhadores rurais sem terra ocuparam a fazenda Nova Pontal, no distrito de Rosana, no Pontal do Paranapanema. A UDR introduziu homens armados na fazenda improdutiva, enquanto esperava pelos soldados da Polícia Militar, os quais expulsaram os "invasores" sob a proteção da justiça, mostrando claramente como o Estado estava pronto para defender os interesses dos grandes proprietários de terra (SOUZA, 2014). Ao longo da história de oposição entre o MST e a UDR, o que verificamos é que o MST se depara com violentas repressões, inúmeras prisões e assassinatos.

Paralelamente a difusão da violência no campo, a UDR buscou garantir a presença de seu representante no cenário político nacional, em todas as instâncias, inicialmente angariando fundos para as campanhas eleitorais para deputados federias, senadores, deputados estaduais, governadores e presidente da república. A partir da década de 1990, empresas simpatizantes e que de alguma forma tinha seus interesses representados pelos parlamentares ruralistas, passam a contribuir com doações, de forma generosa, para suas campanhas eleitorais.

\section{A BANCADA RURALISTA E OS FINANCIAMENTOS DE CAMPANHAS ELEITORAIS}

Para garantir a presença de representantes no Congresso Nacional e nos altos cargos do Governo, principalmente em Ministérios e Secretarias de Estado, com o intuito de garantir seus interesses, os ruralistas sempre criaram mecanismos para se perpetuarem no poder. Um desses mecanismos tem sido a associação com o grande capital, que concede ajuda financeira para as campanhas eleitorais.

De acordo com dados do Departamento Intersindical de Assessoria Parlamentar (2011), 149 deputados federais e 18 senadores integraram a bancada ruralista, perfazendo $29 \%$ da Câmara e $22 \%$ do Senado, na legislatura de $2010-2014^{13}$, o que garante a aprovação

\footnotetext{
${ }^{13}$ Não há um número exato de parlamentares que compõe a bancada ruralista ou de qualquer outra bancada em cada período, pois não se trata de uma organização formal. O Departamento Intersindical de Assessoria Parlamentar - DIAP - (2011) classifica como integrante da bancada ruralista aquele parlamentar que, mesmo não sendo proprietário rural ou da área de agronegócios, assume sem constrangimento a defesa dos pleitos da bancada, não apenas em plenários e nas comissões, mas em entrevistas à imprensa e nas manifestações de plenário.
} 
de Projetos e Leis que atendam aos interesses dos agentes hegemônicos do agronegócio brasileiro.

Analisando o Mapa 1, pode-se verificar que são nos estados de Minas Gerais e Bahia que existem o maior número de deputados compondo a bancada ruralista, em termos absolutos, totalizando 27 e 17 deputados, respectivamente. No entanto, estabelecendo-se uma relação entre o número de deputados de cada estado e o número de ruralistas, verifica-se que a maior porcentagem destes se encontra nos estados de Mato Grosso e Tocantins, em que aproximadamente $70 \%$ dos deputados são ruralistas, sendo que nos dois últimos estados a expansão do agronegócio é mais acentuada. Apenas os estados de Amapá e Amazonas, na região Norte, bem como Rio de Janeiro e Espírito Santos, no Sudeste não apresentam deputados na bancada ruralista, no período de 2011 a 2014.

\section{Mapa 1 - Bancada Ruralista na Câmara dos Deputados e no Senado:} mandato 2011-2014

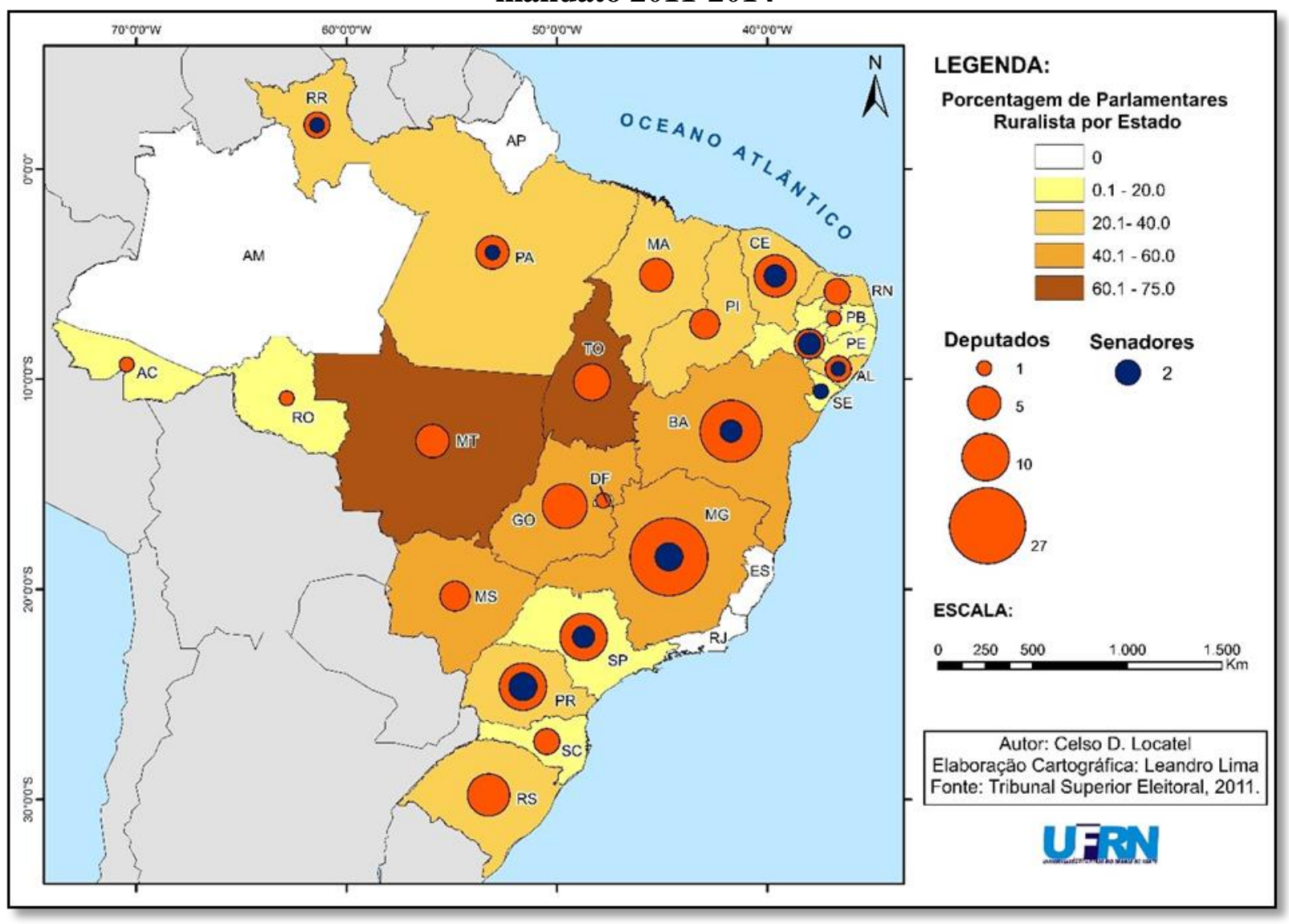

Com relação aos senadores que compõem a bancada ruralista, são os estados do Paraná, Minas Gerais, com 3 senadores, Bahia, Ceará, Pernambuco e São Paulo que apresentam 2 de seus 3 senadores na bancada ruralista, no período 2011-2014. Isto se deve em 
grande medida à pressão exercida por parte dos produtores de soja nas regiões Norte e Centro-Oeste, e no caso específico de Alagoas em razão dos interesses do setor sucroalcooleiro.

De acordo com o Departamento Intersindical de Assessoria Parlamentar - DIAP (2011), na legislatura 2011-2014 a bancada ruralista era composta da seguinte forma: o estado do Acre teve um deputado do PSC; o estado de Alagoas possuía três deputados, sendo um do PP, um do PTB e um do PMDB; o estado da Bahia teve 17 deputados compondo a bancada ruralista, sendo um do PSDB, três do PMDB, quatro do DEM, quatro do PDT, dois do PR, três do PP e um do PSC; pelo estado do Ceará foram eleitos oito deputados, sendo quatro do PMDB, um do PTB, um do PP, um do PSDB e um do PR; pelo Distrito Federal foi eleito apenas um deputado pelo PMN; o estado de Goiás teve nove deputados eleitos que compunham a bancada ruralista, dos quais dois eram do PSDB, dois do PMDB, dois do DEM, um do PTB, um do PP e um do PR; pelo estado do Maranhão foram eleitos cinco deputados, sendo um do PSDB, um do PTdoB, um do PTB, um do PMDB e um do PR; o estado de Minas Gerais teve 27 deputados compondo a bancada ruralista, dos quais seis eram do PMDB, três do PSDB, três do DEM, cinco do PR, dois do PDT, dois do PPS, quatro do PP, um do PSC e um do PMN; pelo estado do Mato Grosso do Sul foram eleitos quatro deputados ruralistas, dos quais um era do PR, um do DEM, um do PMDB e um do PSDB; pelo Mato Grosso se elegeram cinco deputados ruralistas, sendo um do PMDB, um do PP, dois do PR e um do DEM; o estado do Pará teve também cinco deputados da bancada ruralista, com um do PMDB, um do PDT, um do PTB, um do DEM e um do PSDB; pela Paraíba foi eleito apenas um deputado pelo PR; por Pernambuco elegeram-se quatro deputados, sendo um do DEM, um do PSB, um do PR e um do PSDB; pelo estado do Piauí elegeram-se quatro deputados, sendo um do PSB, um do PP, um do DEM e um do PMDB; pelo Paraná foram eleitos 11 deputados ruralistas, sendo um filiado ao DEM, um ao PTB, um ao PPS, dois ao PSC, dois ao PSDB, um ao PMDB, dois ao PP e um ao PSB; pelo Rio Grande do Norte elegeram-se três deputados, sendo um do DEM, um do PMDB e um do PR; o estado de Rondônia teve apenas um deputado eleito compondo a referida bancada, cujo partido era o PPS; por Roraima elegeram-se três deputados, um do PRB, um do DEM e um do PP; pelo Rio Grande do Sul foram eleitos oito deputados, dos quais quatro eram do PP, um do PDT, um do PSDB, um do DEM e um do PTB; por Santa Catarina elegeram-se três deputados, dois do PMDB e um do PP; por Sergipe elegeu-se apenas um deputado ruralista do PMDB; no estado de São Paulo 
foram eleitos dez deputados ruralistas, sendo um do PP, um do PPS, três do PSDB, um do PMDB, um do PR, um do PTB e dois do DEM; do estado de Tocantins elegeram-se seis deputado da banca ruralista, dos quais um era do PPS, um do PSDB, um do DEM, um do PMDB, um do PSB e um do PP.

Já para o Senado Federal, pelo estado de Alagoas foram eleitos dois senadores, um do PP e outro do PMDB; pelo Amapá foi eleito um senador do PMDB; pela Bahia elegeu-se também um senador do PDT; pelo Ceará um eleito do PMDB; por Goiás, um senador do PSDB; por Mato Grosso elegeram-se dois senadores ruralistas, sendo um do PR e o outro do DEM; pelo Pará, elegeu-se apenas um senador ruralista do PSDB; pela Paraíba, um do PMDB; pelo Piauí, um do PTB; pelo Paraná, um do PSDB; pelo Rio Grande do Norte, um do PMDB, que tornou-se ministro da Previdência Social; por Rondônia, um do PP; por Roraima, um do PTB; por Santa Carina, um senador ruralista do PMDB e; por Tocantins, dois senadores da bancada ruralista, sendo um do DEM e outro do PMDB.

Observando as informações representadas no Mapa 1 e no Mapa 2, percebe-se que houve um aumento significativo da bancada ruralista no Congresso Nacional na legislatura 2015-2018, em relação à 2011-2014, uma vez que o número total passou de 167 para 222 parlamentares, sendo 201 deputados e 11 senadores, correspondendo a 39\% da Câmara e a $13 \%$ do Senado.

Em números absolutos estão no topo do ranking os estados de Minas Gerais e Paraná, com 30 e 17 deputados, respectivamente. Em termos relativos, se destacam os estados de Mato Grosso, com 87,5\% dos deputados compondo a bancada ruralista e Tocantins com 75\% dos seus representantes na Câmara Federal. Nos quatro estados que se destacam nesse ranking o agronegócio tem um peso importante na economia dos mesmos. 
Mapa 2 - Bancada Ruralista na Câmara dos Deputados e no Senado: mandato 2015-2018

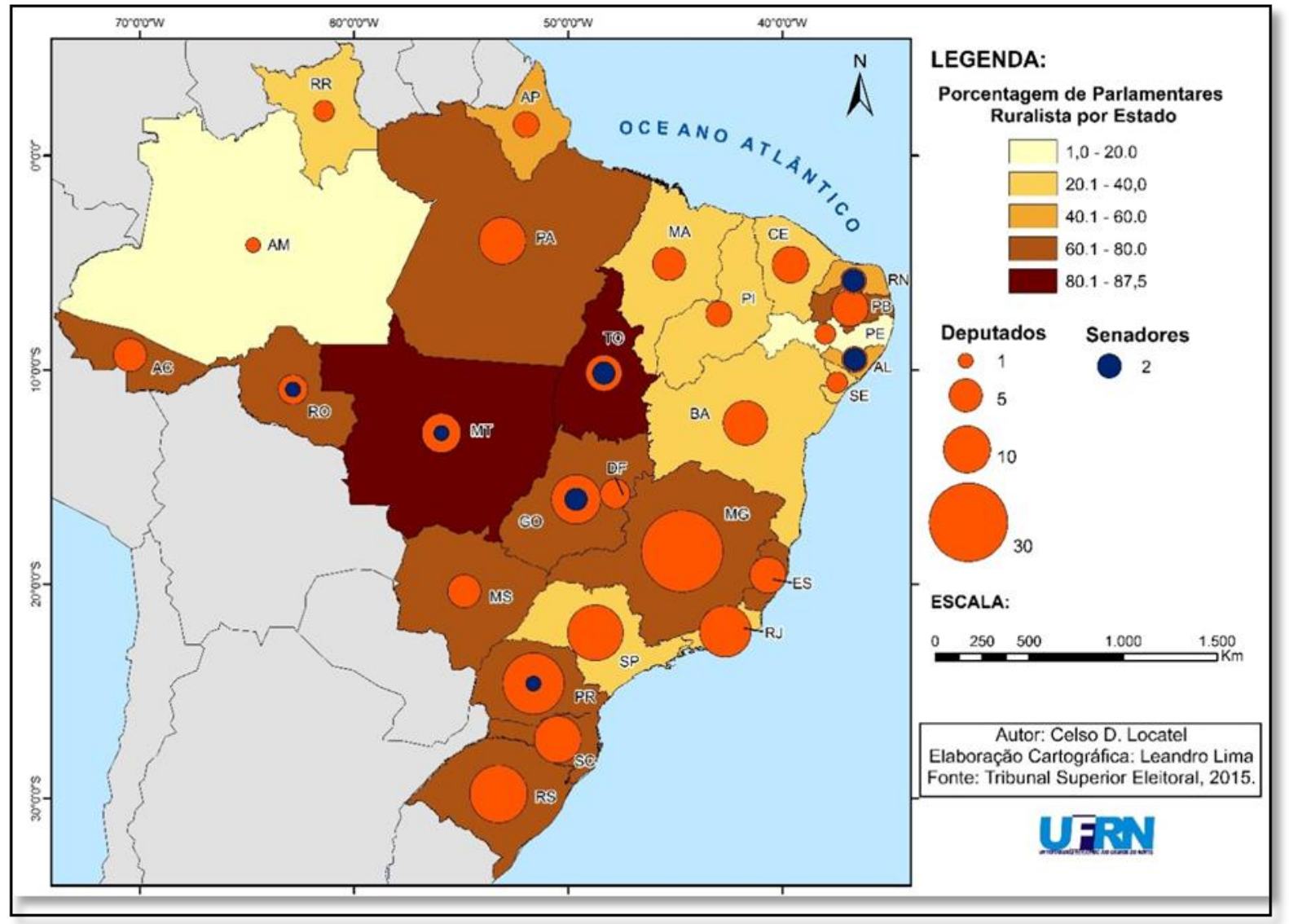

Considerando os dados do Departamento Intersindical de Assessoria Parlamentar DIAP - (2015), na atual legislatura (2015-2018) o estado do Acre possui cinco deputados distribuídos pelo PMDB, PRB, PSB, PSDB e PT, cada partido com um legislador. O estado de Alagoas possui três deputados ruralista, sendo um do PMDB, um do PP e outro do PROS. No estado do Amazonas foi identificado apenas um deputado da bancada ruralista filiado ao PSD. Do Amapá são três deputados, um do PDT, um do PRB e outro do PTB. O estado da Bahia conta com nove deputados nessa bancada, dos quais um é do DEM, um do PDT, dois do PR, três do PSD, um do PSDB e um do PTB. Do estado do Ceará foram identificados seis deputados, distribuídos pelo PMB, PSB, PSDB, SD e PMDB, sendo que somente esse último partido conta com dois deputados. O Distrito Federal possui quatro deputados nessa bancada, distribuídos pelo DEM, PMDB, PSDB e SD. No estado do Espírito Santo foram identificados seis deputados, sendo um do PDT, um do PP, um do PROS, um do PV e um do SD. No estado de Goiás são onze deputados ruralistas, dos quais um pertence ao PDT, dois ao PMDB, um ao PP, um ao PR, um ao PSD, três ao PSDB, um ao PTB e um ao SD. Compondo a bancada ruralista pelo estado do Maranhão são cinco deputados, filiados ao PDT, ao PEN, ao 
PMB, ao PMDB e ao PRB. Já o estado de Minas Gerais, com o maior número de ruralistas, possui 30 deputados, sendo dois do DEM, três do PMB, cinco do PMDB, três do PP, três do PR, três do PSD, quatro do PSDB, dois do PT, e os partidos PDT, PHS, PSB, PSC e SD possuem apenas um deputado cada um. O estado de Mato Grosso do Sul tem cinco deputados ruralistas, um do PDT, dois do PMDB, um do PSB e um do PSDB. Por Mato Grosso são sete, dos oito deputados federais que o estado tem na Câmara, sendo o estado que proporcionalmente está no topo do ranking, dos quais um é do PMB, um do PMDB, dois do PSB, um do PSC, um do PSDB e um do PT. O estado do Pará possui dez deputados ruralistas, sendo um do DEM, três do PMDB, um do PPS, um do PR, dois do PSD, um do PTB e um do SD. No estado da Paraíba são seis deputados, um do DEM, dois do PMDB, um do PR, um do PTB e um do SD. O estado de Pernambuco possui apenas dois deputados ruralistas, um do PHS e um do PSB. Pelo estado do Piauí são três, filiados ao PSB, ao PSD e ao PTB. O estado do Paraná, segundo no ranking em termos absolutos, possui 17 deputados ruralistas, sendo dois do PMDB, três do PP, dois do PR, dois do PSB, dois do PSDB e os outros seis são filiados ao PHS, ao PMB, ao PPS, ao PSC, ao PSD e ao SD. O estado do Rio de Janeiro, que no período 2011-2014 não possuía nenhum deputado na bancada ruralista, passou a ter 12, assim distribuídos: seis no PMDB, dois no PR, um no PRB, dois no PSD e um no SD. Do Rio Grande do Norte são três deputados, um do PMDB, um do PP e um do PR. O estado de Rondônia é representado por quarto deputados ruralistas, dois do PMDB, um do PR e um do PTB. No estado de Roraima são apenas dois deputados, um do PMB e outro do PMDB. No estado do Rio Grande do Sul, terceira maior bancada, são 15 deputados, dos quais quatro são filiados ao PMDB, seis ao PP, dois ao PDT, e o DEM, oPSB e o PSDB possuem um cada um. O estado se Santa Catarina tem dez deputados ruralistas, sendo cinco do PMDB e os outros cinco distribuídos pelo PP, PR, PSD, PSDB e PT. Pelo estado de Sergipe são dois deputados, um do PRB e um do SD. Por São Paulo são 14 deputados, dois quais dois são filiados ao DEM, dois ao PSC e os demais pertencem ao PMDB, PP, PR, PRB, PSD, PSDB, PT, PTB, PV e SD. O estado de Tocantins, dos oito acentos que possui na Câmara dos Deputados, seis estão ocupados com ruralistas, sendo que cada vaga é de um partido diferente: PMB, PMDB, PP, PRB, PSB e PSD.

O que chama a atenção na distribuição dos deputados ruralistas por partidos políticos são os casos do PMDB, que conta com 44 parlamentares, mais de 66\% do total de deputados peemedebistas, do PP, com mais 52\% dos seus deputados, o PSD com mais de $45 \%$ e do 
PSDB, com mais de 33\%. Esses quatro partidos somam 98 parlamentares ruralistas. Da mesma foram, chama atenção o fato de seis deputados do Partido dos Trabalhadores estarem compondo a bancada ruralista.

Entre os financiadores de campanha que estão diretamente envolvidos com o agronegócio, merece destaque a atuação de algumas empresas que têm financiado um grande número parlamentares, os quais certamente ao serem eleitos buscam se organizar de modo a intervir em favor das causas e objetivos de seus financiadores, o que justificaria os significativos e vultosos valores doados para as campanhas eleitorais de vários parlamentares por um único grupo econômico.

Analisado os dados do Tribunal Superior Eleitoral (2010), contata-se que a empresa Bunge Fertilizantes S/A, fez doações para financiar a campanha de 11 parlamentares da bancada ruralista; a JBS S/A ${ }^{14}$, fez doações para um total de 17 parlamentares; as empresas do setor de celulose realizaram doações para as campanhas de 11 parlamentares, sendo que a empresa Fibria Celulose sozinha disponibilizou recursos para a campanha de quatro parlamentares; a Usina Coruripe Açúcar e Álcool S/A, fez doações para cinco campanhas de parlamentares, sendo que o setor sucroalcooleiro, como um todo, efetuou doações para 16 deputados federais e para dois senadores da república; além da empresa Sucocítrico Cutrale LTDA, principal produtora de suco concentrado de laranja no Brasil, fez doações para as campanhas de três parlamentares eleitos em 2010.

Quando se analisa o valor total gasto por esse grupo de empresas, na campanha eleitoral de 2010, constata-se que a Bunge Fertilizantes gastou um total de R $\$ 2.833 .000,00$ em doações para campanhas eleitorais; a JBS S/A gastou o equivalente à R \$ 30.093.000,00; entre as empresas do setor de papel e celulose, a Fibria S/A doou o montante de R\$ 4.745.242,43; a Sucocitrico (Cutrale) R\$ 1.960.000,00 e; as empresas do setor Sucroalcooleiro juntas doaram mais de $\mathrm{R} \$ 15.500 .000,00^{15}$. Essas cifras evidenciam os altos valores que as grandes empresas ligadas ao agronegócio utilizam nas campanhas eleitorais no Brasil. Cabe frisar que esses dados são só para exemplificar a influência e ação dessas empresas nos pleitos eleitorais.

\footnotetext{
${ }^{14}$ O grupo controla marcas como Swift, Friboi, Maturatta, Cabana Las Lilas, Pilgrim's, Gold Kist Farms, Pierce e 1855. A companhia atua em 22 países de cinco continentes.

${ }^{15}$ Não foi possível auferir o valor exato, pois os dados de três empresas não estavam disponíveis, no site do TSE. 
Analisando os dados do pleito eleitoral de 2014, verifica-se que a JBS S/A contribuiu com doações para a campanha de 29 deputados eleitos, a Cutrale para quatro deputados eleitos, a Fibria colaborou com doações para a campanha de nove deputados eleitos e o setor agroenergético ajudou a eleger mais de 20 deputados.

Quando se analisa os valores contata-se que a empresa Fibria S/A, uma das maiores do setor de papel e celulose, doou $\mathrm{R} \$ 4.375 .200,00$ para campanhas eleitorais em 2014; as empresas de fertilizantes doaram R \$ 648.366,34; o grupo JBS S/A efetuou doações no montante de $\mathrm{R} \$ 76.704 .441,50$, dos quais $\mathrm{R} \$ 17.464 .265,38$ para a campanha de deputados eleitos, a Cutrale, do setor de suco de laranja, efetuou doações no montante de $\mathrm{R} \$$ 6.565.000,00, basicamente para campanha de candidatos do Estado de São Paulo, o setor sucroalcooleiro doou mais de $\mathrm{R} \$ 7.500 .000,00^{16}$. Quando se analisa os dados de prestação de contas dos candidatos à deputados federais eleitos verifica-se que esse grupo de empresas doaram um valor superior a $\mathrm{R} \$ 39,5$ milhões (TSE, 2014), quantia muito superior as doações realizadas na campanha de 2010.

Dentre as diversas empresas que financiaram as campanhas eleitorais dos ruralistas deputados e senadores - também constatamos os investimentos feitos por diferentes ramos produtivos, como da construção civil, mineração, redes de revendedoras de automóveis, bancos e de postos de combustíveis, evidenciando que não somente os segmentos vinculados diretamente ao agronegócio se beneficiam da manutenção do lobby constituído pela bancada ruralista no Congresso Nacional, o que evidencia que os ruralistas asseguram a representação de interesses de outros segmentos hegemônicos também. Isto é, tais empresas que são partes interessadas na manutenção das oligarquias rurais no poder público também exercem uma grande influência na tomada de decisões, sobretudo por meio da pressão - ostensiva e/ou velada sobre os candidatos apoiados.

\section{CONSIDERAÇÕES FINAIS}

Entender a manutenção do desequilíbrio das políticas executadas pelo Estado brasileiro, voltadas para os segmentos agropecuários, só é possível analisando a estrutura de poder que envolve o funcionamento do Estado, considerando a atuação dos vários grupos no cenário político, entre eles os ruralistas, que mesmo sendo de origem pluripartidária, se

\footnotetext{
${ }^{16}$ Não foi possível chegar ao valor exato de doações das empresas desse setor, pois alguns dados não estão disponíveis no site do TSE.
}

Sociedade e Território - Natal. Vol. 28, N. 2, p. 57 - 81. Jun./Dez. de 2016 
apresentam como um grupo coeso, organizado e com forte poder de pressão na formulação das políticas públicas. A banca ruralista tem atuado, prioritariamente, com o intuito de mudança da legislação trabalhista, fundiária, tributária, indigenista e quilombola, assim como atuou para a aprovação do novo Código Florestal, em 2012, que flexibilizou a Lei Ambiental brasileira, usando como principal argumento o aumento da produtividade e competitividade do setor agropecuário.

Quando se analisa os dados referentes ao financiamento agropecuário, por exemplo, verifica-se que aproximadamente $80 \%$ dos recursos públicos, destinados para esse fim, são apropriados pelos segmentos empresariais, que correspondem a menos de $20 \%$ dos estabelecimentos agropecuários brasileiros, o que confirma que as políticas agrícolas se mantêm como um sistema de privilégios posto à serviço do capital agromercantil.

Nota-se que com a descentralização administrativa, ocorrida a partir da Constituição de 1988, muitas competências, antes do Governo Federal, foram repassadas aos estados e municípios. Devido à estrutura político-administrativa do país, em especial ao grande número de micro-municípios, os quais dependem quase que exclusivamente da transferência de recursos da União, e por causa da ausência de uma esfera administrativa regional, que pudesse diminuir a distância entre os estados e as prefeituras, as novas funções estaduais e municipais não têm sido desempenhadas a contento para dar suporte para os agricultores camponeses, o que demonstra a existência de sérios problemas na estrutura administrativa. Porém, as políticas voltadas para o segmento da agricultura empresarial são bem estruturadas e atendem aos interesses dos grupos hegemônicos, tanto de latifundiários como de empresários dos setores vinculados à agricultura, em especial o setor agroenergético, agroexportador e de papel e celulose.

As estratégias adotadas pelas oligarquias rurais surtiram bons resultados para as mesmas, uma vez que, mesmo com mudanças no cenário político nacional, não houve redução de privilégios para os empresários do agronegócio no Brasil. A manutenção dos privilégios para a agricultura empresarial está diretamente associada às forças econômicas representadas pelas grandes empresas, que por sua vez passam a financiar as campanhas eleitorais, as quais se tornaram milionárias, haja vista o seu sistema de financiamento.

Assim, constata-se que houve mudanças na lei máxima do país, na Constituição Federal; na forma de organizar os serviços públicos de assistência técnica e extensão rural, com a descentralização da gestão pública; na formulação das políticas de financiamento 
agrícola, com a criação de política específica para a agricultura familiar; no tratamento da questão agrária, como a formulação de planos nacionais de reforma agrária; na forma de atuação dos agentes hegemônicos, como as grandes empresas financiando as campanhas eleitorais de muitos políticos, para garantirem a defesa de seus interesses na esfera de tomada de decisão.

Por outro lado, houve a manutenção da estrutura fundiária, sem que a aplicação da política de reforma agrária fosse suficiente para provocar mudanças significativas, contribuindo para a justiça social no campo; manteve-se o poder das oligarquias rurais, que têm suas raízes históricas no coronelismo estruturado no período imperial; permanece o uso da força para reprimir os que lutam pelo acesso à terra no campo; além da sujeição dos agricultores camponeses à lógica de acumulação de capital, uma vez que as políticas públicas não garantem a autonomia dos mesmos, pois os mercados continuam monopolizados pelos agentes hegemônicos, que se apropriam de toda a renda gerada pelo trabalho agrícola.

No entanto, mesmo que os representantes das oligarquias rurais e do grande capital ligado ao agronegócio no Congresso Nacional e sua principal instituição de representação de classe, a Confederação Nacional de Agricultores (CNA), apontem as vantagens e os dados oficiais demonstrem que o agronegócio é o setor que sustenta a balança comercial brasileira, os mesmos não podem esconder as contradições existentes no campo brasileiro, como a superexploração da força de trabalho, poucos recursos para a agricultura camponesa, concentração fundiária, violência no campo frente aos conflitos agrários e ambientais, além de a agricultura familiar camponesa ser a principal responsável pela produção dos alimentos consumidos no território nacional.

\section{REFERÊNCIAS}

ANDRADE, K. F. A Voz do "Agro": O discurso da CNA e a representação dos interesses do patronato rural no Brasil. Monografia (Graduação em Agronomia). Instituto de Agronomia, Universidade Federal Rural do Rio de Janeiro, Seropédica, RJ, 2013.

BRUNO, Regina. Revisitando a UDR: ação política, ideologia e representação. Revista Ins. Est. Bras. São Paulo, 1996.

CARNEIRO, Olavo Brandão. Patronato Rural e Ação Coletiva.Trabalho publicado no $32^{\circ}$ Encontro Anual da ANPOCS: Caxambu - MG, 2008. Disponível em: <http://r1.ufrrj.br/cpda/wp-content/uploads/2011/09/dissertacao_olavo_carneiro.pdf >. Acesso em 05 de abril de 2013. 
CASTRO, Antonio Barros de. Sete Ensaios sobre a Economia Brasileira. Rio de Janeiro, 1969.

DELGADO, Guilherme da Costa. Capital financeiro e agricultura no Brasil - 1965-1985. São Paulo: Ícone, 1985.

DIAP - Departamento Intersindical de Assessoria Parlamentar.Banca Ruralista aumenta com reforço de novos parlamentares. Acesso em: 10 de jun. 2015. Disponível em: $<$ http://www.diap.org.br/index.php?option=com_content\&view=article\&id=15500>. DIAP - Departamento Intersindical de Assessoria Parlamentar. Bancada ruralista aumenta com o reforço de novos parlamentares (2011). Acesso em: 05 abr. 2014. Disponível em: $<$ http://reporterbrasil.org.br/2011/01/bancada-ruralista-aumenta-com-o-reforco-de-novosparlamentares/>.

FAORO, Raymundo. Os donos do poder. Formação do patronato político brasileiro. Rio de Janeiro, Ed. Globo, 2001.

FURTADO, Celso. Análise do "Modelo" Brasileiro. Rio de Janeiro, Civilização Brasileira, 1972.

FURTADO, Celso. O longo amanhecer: reflexões sobre a formação do Brasil. Rio de Janeiro, Paz e Terra, 1999.

FURTADO, Celso. O mito do desenvolvimento. Rio de Janeiro, Paz e Terra, 1974.

IANNI, Octávio. O colapso do populismo no Brasil.Rio de Janeiro, Civilização Brasileira, 1975.

IBGE - INSTITUTO BRASILEIRO DE GEOGRAFIA E ESTATÍSTICA. Censo Agropecuário de 2006. Acesso contínuo. Disponível em: 〈http://www.sidra.ibge.gov.br/>.

JANOTTI, Maria de Lourdes M. O Coronelismo: uma política de compromissos. São Paulo: Atual, 1992.

LEAL, Victor Nunes.Coronelismo, enxada e voto. Rio de Janeiro: Nova Fronteira, 1997.

LOCATEL, Celso D. Modernização da Agricultura, Políticas Públicas e Ruralidade:

Mudanças e Permanências na Dinâmica Rural das Microrregiões de Jales e de Fernandópolis. UNESP/FCT, Presidente Prudente, 2004 (Tese de Doutorado).

LOCATEL, Celso D.; LOCATEL, Selma A. Aspectos políticos do corenelismo no processo de fundação e ocupação do município de Jales (SP). In: SedevalNardoque, Vagnewr José Moreira, Humberto Perinelli Neto. (Org.). Noroeste Paulista: Praticas e movimentos sociais, trabalhadores e experiência. São Paulo: Outras Expressões, 2013, v. 1, p. 17-44.

MELLO, João Manuel Cardoso. O capitalismo tardio: contribuição à revisão da formação e do desenvolvimento da economia brasileira. São Paulo: Brasiliense, 1994. 
MENDONÇA, Sônia Regina de. O Patronato Rural Brasileiro na atualidade: dois estudos de caso. Anuariodel Centro de Estudios Históricos «Prof. Carlos S. A. Segreti» Córdoba (Argentina), ano 8, $\mathrm{n}^{\circ}$ 8, 2008, 139-159.

MULLER, Charles C. A racionalidade, o poder e a formulação de políticas agrícolas no Brasil. In: VIEIRA, Armando Pereira. Política Agrícola. Lavras: UFLA/FAEPE, 1994.

MÜLLER, Geraldo. Nosso agrário verde-amarelo: contabilizando heranças e sugerindo uma estratégia. Rascunho.Rio Claro: UNESP/IGCE, 1993, nº 27.

PAIVA, Ruy Miller. Modernização e Dualismo Tecnológico na Agricultura. Pesquisa e Planejamento. Rio de Janeiro, IPEA, 1971.

PAIVA, Ruy Miller. Problemas da agricultura brasileira. Rio de Janeiro, MA/SIMA, 1954.

PRADO JÚNIOR, Caio. A Revolução Brasileira. São Paulo, Brasiliense, 1966.

PRADO JUNIOR, Caio. A questão agrária no Brasil. São Paulo: Brasiliense, 1979.

REPORTE BRASIL (2011). Bancada ruralista aumenta com o reforço de novos parlamentares. Disponível em <http://reporterbrasil.org.br/2011/01/bancada-ruralistaaumenta-com-o-reforco-de-novos-parlamentares/>. Acesso em 10 março de 2014.

SORJ, Bernardo. Estado e Classes sociais na agricultura brasileira. Rio de Janeiro: Zahar, 1980.

SOUZA, Sônia Maria Ribeiro de. O MST e a mídia: o fato e a notícia. Disponível em: $<$ http://revista.fct.unesp.br/index.php/pegada/article/viewFile/791/814>. Acesso em: 05 de abril de 2014.

TAVARES, Maria Conceição. Da substituição de importações ao capitalismo financeiro: ensaios sobre economia brasileira. Rio de Janeiro, Zahar, 1983.

TSE - TRIBUNAL SUPERIOR ELEITORAL. Estatísticas de prestações de contas de eleições anteriores. Disponível em: <http://www.tse.jus.br/eleicoes/estatisticas>. Acesso em: 25 de março de 2014.

VEIGA, José Eli. et al. O Brasil rural precisa de uma estratégia de desenvolvimento. Brasília, Convenio FIPE - IICA (MDA/CNDRS/NEAD), 2001.

Recebido em Setembro de 2016

Aprovado em Novembro de 2016

Publicado em Dezembro de 2016 